\title{
Renal and Paraspinal Mass in a Patient with Granulomatosis with Polyangiitis: Does Biopsy of one Mass Reflect Pathology in the other
}

\author{
Homa Timlin $^{1 *}$, Michael Phillips ${ }^{1}$, Jeremy Hackworth ${ }^{2}$, Duvuru Geetha ${ }^{1}$ \\ ${ }^{1}$ Department of Rheumatology, Johns Hopkins University School of Medicine, Baltimore, MD \\ ${ }^{2}$ Department of Radiology, Johns Hopkins University School of Medicine, Baltimore, MD.
}

Received: March 9, 2017; Accepted: April 10, 2017; Published: May 16, 2017

*Corresponding author: Homa Timlin MD MSc, Johns Hopkins Division of Rheumatology, 5501 Hopkins Bayview, Circle/Asthma and Allergy Building, Suite 1B.1, Baltimore, MD 21224.

\section{Exceptional Case}

\section{Abstract}

Granulomatosis with Polyangiitis (GPA) is a necrotizing vacuities affecting medium and small sized blood vessels and produces necrotizing granulomas often involving the upper and lower respiratory tract. GPA can present as tumor like masses in the breast and kidney [1]. However, an association between GPA and renal cell cancer has also been reported [2]. We report a GPA patient who presented with abdominal pain and was found to have a renal and paraspinal mass which were biopsied revealing two distinct pathologic entities.

A 74 year old Caucasian male was diagnosed with PR3 ANCA positive GPA in 2010 when he presented with acute kidney injury and had biopsy proven pauci-immune glomerulonephritis. He achieved disease remission with remission induction therapy with glucocorticoids and Cyclophosphamide. He experienced a renal relapse in 2013 and achieved disease remission with glucocorticoids and rituximab. He presented in March 2016 with abdominal pain and was found to have a right renal mass and a paraspinal mass. Ultrasound guided biopsy of the renal mass revealed clear cell renal cell carcinoma. Four days after the biopsy, he was admitted with fatigue, night sweats and arthralgias. Laboratory data were notable for a rise in serum creatinine, proteinuria and hematuria. His inflammatory markers were elevated and his PR3 ANCA titer had increased by two fold. His B cells showed reconstitution. He underwent biopsy of his paraspinal mass which revealed necrotizing granuloma with no evidence of infection or malignancy. He was treated with glucocorticoids and rituximab. His serum creatinine improved and his hematuria and proteinuria resolved. His inflammatory markers normalized and his PR3 ANCA titer became negative. His repeat CT scan revealed improvement in the size of the paraspinal mass (Figure 1 and 2). He subsequently underwent cryoablation of his right renal mass in October 2016.

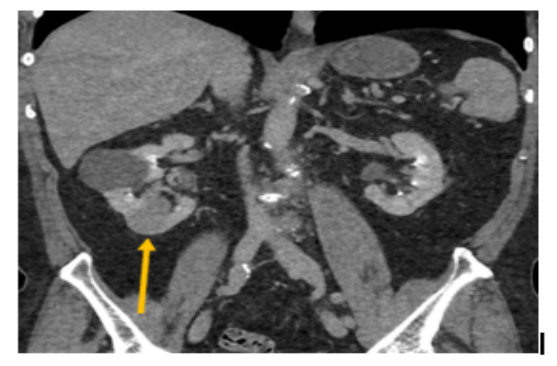

Figure 1: Right Renal Cell Carcinoma mass.

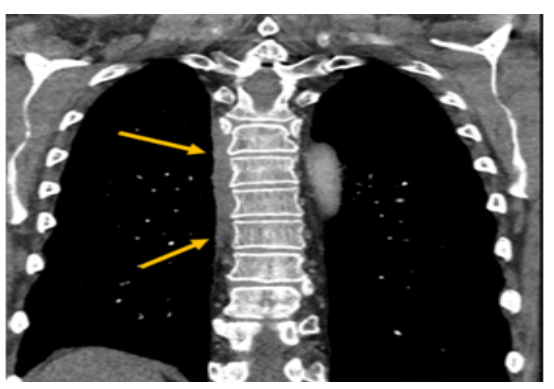

Figure 2: Initial Coronal Paraspinal mass March 2016

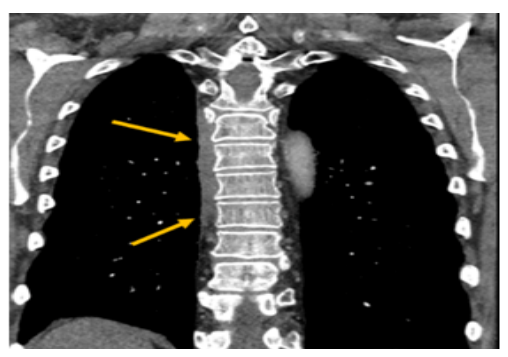

Figure 3: Follow up imaging of Coronal Paraspinal mass, August 2016. 
PR ANCA positive GPA patients often have a relapsing disease course with relapse manifestations that are different from the initial presentation. GPA can present as tumor like lesions. These tumor like masses have been mostly described in kidney and breast but have also been described in pancreas, lung, orbit, brain and mediastinum [1, 3, 4, 5]. A paraspinal location of such masses has not been described so far. Malignancy should be included in the differential diagnosis of GPA patients presenting with a mass lesion. . Tatsis et al first described an association between renal cell carcinoma and GPA [2]. Subsequently there a have been other reports of renal cell carcinoma in GPA patients [6]. Tissue biopsy obtained from an affected organ confirms the definitive diagnosis.

In our patient, he was at high risk of disease relapse with doubling of PR3 ANCA titer and B cell reconstitution and he was at high risk of malignancy and therefore, a decision was made to obtain tissue biopsy for both his renal and paraspinal mass. His GPA responded well to rituximab and glucocorticoids and his renal cell carcinoma were treated with cryoablation. It is interesting to speculate that his renal cell carcinoma might have been a trigger for relapse of his GPA.

Key words: Granulomatosis with Polyangiitis, Paraspinal mass, Biopsy, immunosuppression.

\section{References}

1. Kariv R, Sidi Y, Gur H. Systemic vasculitis presenting as a tumorlike lesion. Four case reports andan analysis of 79 reported cases. Medicine (Baltimore). 2000;79(6):349-359.

2. Tatsis E, Reinhold-Keller E, Steindorf K, Feller AC, Gross WL. Wegener's granulomatosisassociated with renal cell carcinoma. Arthritis Rheum. 1999;42(4):751-756.

3. Fairbanks KD, Hellmann DB, Fishman EK, Ali SZ, Stone JH. Wegener's granulomatosis presentingas a renal mass. AJR Am J Roentgenol. 2000;174(6):1597-1598.

4. Ward A, Konya C, Mark EJ, Rosen S. Granulomatosis with polyangiitis presenting as a renaltumor. Am J Surg Pathol. 2014;38(10):14441448. doi: 10.1097/PAS.0000000000000294.

5. Edgar JD, Rooney DP, McNamee P, McNeill TA. An association between ANCA positive renal disease and malignancy. Clin Nephrol. 1993;40(1):22-25.

6. Bumbasirevic U, Dragicevic D, Janicic A, Cemerikic-Martinovic V, Cekerevac M, et al. Renal cancer and Wegener's granulomatosis: a case report. World J Surg Oncol. 2011;9:165. doi:10.1186/1477-7819-9165. 